\title{
Energy-Economic Optimization of Thin Layer Photovoltaic on Domes and Cylindrical Towers
}

\author{
Mostafa Esmaeili Shayan*, Gholamhassan Najafi**: \\ * Mechanical and Biosystems Engineering, Ph.D. student of renewable energy engineering, Tarbiat Modares University, \\ 14115-111, Tehran, Iran \\ ** Mechanical and Biosystems Engineering, Ph.D. Associate Professor, Tarbiat Modares University, 14115-111, Tehran, Iran \\ (Mostafa.esmaeili@modares.ac.ir, g.najafi@modares.ac.ir) \\ ${ }^{\ddagger}$ Corresponding Author; 14115-111, Tehran, Iran, Tel: +98 48292004,
}

Fax: +98 48292004, g.najafi@modares.ac.ir

Received: 03.06.2019 Accepted:15.06.2019

\begin{abstract}
In Building Integrated Photovoltaic Systems, Thin Layer Photovoltaic Integrated into the building which regularly is the outside Weathering Skin. Conventional photovoltaic systems cannot be applied to arched facades. During this research, photovoltaic system supported elastic solar panels were evaluated on a Model layer of $1 \mathrm{~m} 2$ and $56 \mathrm{~W}$. A flexible system was analyzed in real terms on a flat, cylindrical and hemispherical surface. Environmental data were communicated on-line into LabVIEW software. The smallest quantity of fill factor (FF) relates to a flat surface and also the systems once installed on the cylindrical and hemispherical surfaces, have a fill factor of 0.88 and 0.84 , respectively. The maximum power related to system deployment on the cylinder surface is $59.87 \mathrm{~W}$, whereas the minimum power of the system when deployed on the flat surface is $57.84 \mathrm{~W}$. The most effective power in the RSM deployment on the hemispherical surface is equal to $61.14 \mathrm{~W}$. The system's performance under standard conditions on the cylinder and dome surfaces are measured $7.45 \%$. The quantity of laboratory power output was related to the hemispherical, cylindrical, and flat surfaces, and its value is $46.7 \mathrm{~W}, 55.1 \mathrm{~W}$ and $57.5 \mathrm{~W}$ respectively. The economic justification was ranked based on the hemispherical, cylindrical and flat surfaces, respectively. According to the Taguchi, the maximum power reported $59.87 \mathrm{~W}$ at the cylindrical that doesn't match the actual test model. The second power level has been reported on a hemisphere, which is corresponded to the actual test.
\end{abstract}

Keywords Thin Layer; Photovoltaic; LabVIEW; dome surfaces; Taguchi.

\section{Introduction}

The Kyoto Protocol is an international treaty to reduce greenhouse gas emissions and thereby to reduce the effects of global warming. Solar PV generation is a promising renewable and clean source of energy because a PV system converts energy directly into electricity. Such PV systems are environmentally friendly, quiet, easy to maintain, stable and secure, and do not emit greenhouse gases or carbon dioxide when they generate electrical energy [1]. European countries plan to provide close to $50 \%$ of their low-pressure heat demand by solar thermal sources by 2030 [2], but highpotential photovoltaic technology can contribute up to $5 \%$ by 2030 and up to $11 \%$ by 2050 of electricity demand in Europe [3]. Photovoltaic (PV) technology received a great interest worldwide over the last decades. It is expected that solar PV will be the cheapest renewable power technology in the near future because of the deep cost reduction of the PV components [4]. Energy sector poses the largest source of greenhouse gas emissions, and energy supply from fossil fuels has confronted the environment with crises, emitting millions of greenhouse gases into the atmosphere [7]. BIPV is gradually being used in buildings as a primary or alternative source of energy. Distinctive parameters need to be considered over for the proper capacity of the BIPV cells. The BIPV System additionally reduces heat transfer into buildings and permits natural daylight to enter through it and in addition supports to increase sound and heat insulation of the building [8] However, the operating temperature of the PV cells need to be controlled to stay far away from the degradation of performance because of excess temperature [9]. One planned technique to remain removed from arbitrary warming temperatures from unabsorbed lights is to recognize a ventilation strategy through natural or forced convection on 
the PV panels [10], [11]. Various models have been considered to reduce the temperature at the panels to half. Then again, the introduction of the PV cells to a great extent is influenced by the incident sunlight and in this manner their electrical power yields. While the energy intensity index in Iran has risen from 100 to 300 from 1974 to 1994, the average energy intensity in the world is 0.4 and this figure is more than 0.6 in Iran [12]. Rising energy consumption, disadvantages and limitations of fossil fuels have increased the tendency of using renewable energy, especially solar energy [13] so that per capita energy production increased over 2000-2007 [14]. The increase is projected to rise by more than $60 \%$ of consumption amount in 2000 by 2030 . In providing renewable energy and given the potential of Iran, solar energy is environmentally friendly owing to not generating co2; it also leads to maintaining natural resources, to rehabilitate lands, to reduce power transmission lines, to increase regional autonomy in energy supply, to increase the speed of electricity transmission to rural areas, and to be cost-effective [6].The appointed inflation rate in this section based on the average inflation rate in the last five years between 2011 and 2016 associating with goods category of water, electricity, and fuel, on average, was $10 \%$ [15]. Research studies reveal that annually the number of sunny days and hours in Tehran is almost 313 days and 1742 hours, respectively. Its changing pattern in Iran is declining from the south-east to the northwest and is rising typically from the west to the east [16]. Though system performance is optimized by many different techniques, intelligent system design such as Artificial Neural Network (ANN) is one of the useful techniques to optimize efficiency by modelling, simulating, and controlling the system [22]. The RSM is a powerful statistical method, which can be used to establish an empirical model by obtaining the relationship between the system response and its design variables [4].

Hong et al. used the Taguchi test analysis method in a solar thermal heater system with L16 (44) orthogonal array [1]. Demiroren and Yilmaz worked with aerodynamic design on hybrid energy systems using flexible panels [24], also Gregg worked on the performance of amorphous silicon-based systems on a large scale and their cost-effectiveness. In a research on the economic justification of using photovoltaic systems relative to household fossil fuels, COMFAR software was utilized [25].

Considering the importance of deploying photovoltaic systems as the body of objects and figures, however, no studies have been conducted on photovoltaic systems deployment on vault and dome structure. The system can be used in traditional cities in Islamic nations, which usually have Hemispherical Roof (domes) and towers, and agricultural sectors to supply biogas reservoirs and granary silos. The aim of this paper is to investigate and analyse the possibilities of flexible solar Conversion system for Electric supply in Curved surfaces. In addition to sustaining the surface-to-surface features, this systems should be able to cover the facade as a layer and generate electrical power. During this study, we have tried to calculate and rate the actual power of utilizing flexible solar power conversion system using technoeconomic assessment methods basis of Taguchi experimental designs and the response Surface level (RSM), adopted to verify the effects of each factor on the design of experiments methods (DOE). To this outcome, NPV, IRR and PP criteria have been employed.

\section{Materials and Methods}

Flexible cells with proper thickness and strength could cover any structure and generate more power with a series connection. Solar energy conversion system based on flexible panels according to Fig.1 includes: geometric structure in cylindrical, hemispherical and flat surfaces, flexible solar module, battery bank, irradiance intensity sensor, temperature sensing element, humidity sensor, anemometer, voltage meter, power amplifier, preparation circuits, battery fuses, analogdigital converter and laptop.

Imposing the test over flat, cylindrical and spherical surfaces, the acquisition of voltage and power data was carried out. Fig. 2 exposes the analysis of some traditional structures to real conditions tested. After modelling the body of the building, the parts that are active in environmental energy are modelled in cylindrical or hemispherical shape and evaluated under real conditions. For this design, the testing surface was developed in $1 \mathrm{~m} 2$ and the design and fabrication of the cylindrical and spherical structures were carried out.

Flexible photovoltaic module was used with the specifications given in Table (1). JNsolar3W-12v solar silicon amorphous photovoltaic element with three junction sites of deposition in a stainless polymer bed and a lock diode were employed to prevent the battery current discharge towards the solar panel in the module.

Table 1. JNsolar $3 \mathrm{~W}-12 \mathrm{v}$ flexible photovoltaic element Characteristics in standard conditions[26].

\begin{tabular}{|c|c|c|}
\hline Characteristic & Unit & Value \\
\hline Dimensions & $\mathrm{mm}$ & $(290 \times 210 \times 5)$ \\
\hline Power at maximum point & $\mathrm{W}$ & 3.5 \\
\hline Open circuit voltage & $\mathrm{V}$ & 14 \\
\hline Short circuit current & $\mathrm{A}$ & 0.3 \\
\hline Voltage at maximum point & $\mathrm{V}$ & 12 \\
\hline Performance & $\%$ & $4-8$ \\
\hline
\end{tabular}

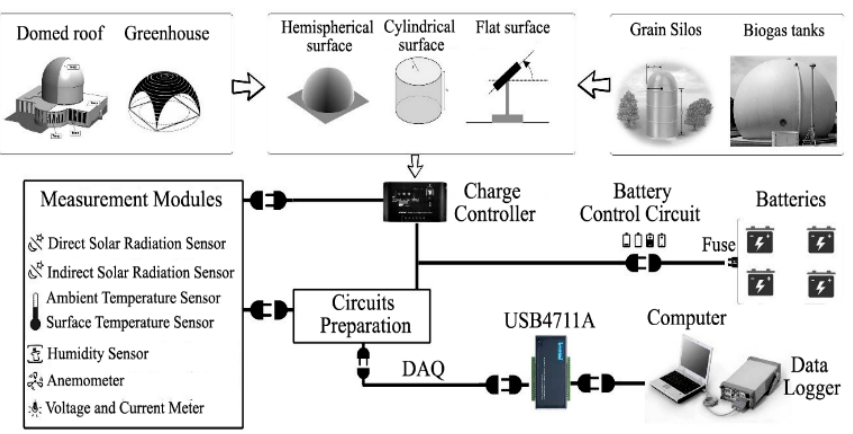

Fig. 1. Flexible photovoltaic system and control equipment. 
INTERNATIONAL JOURNAL Of SMART GRID

Mostafa Esmaeili Shayan and Gholamhassan Najafi, Vol.3, No.2, June, 2019
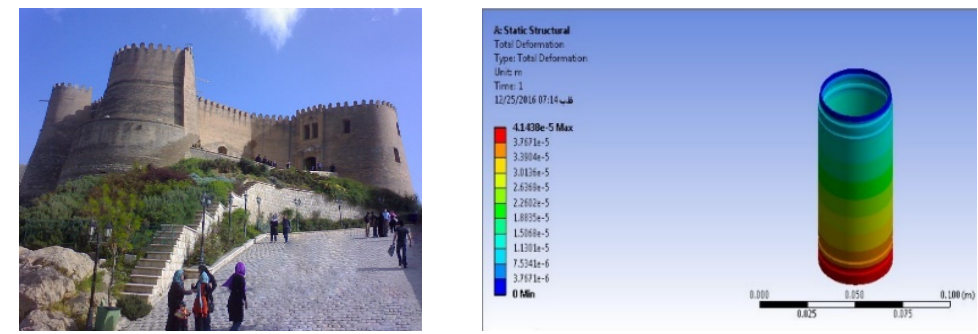

A:Falak-ol-AflakCastle,Lorestan
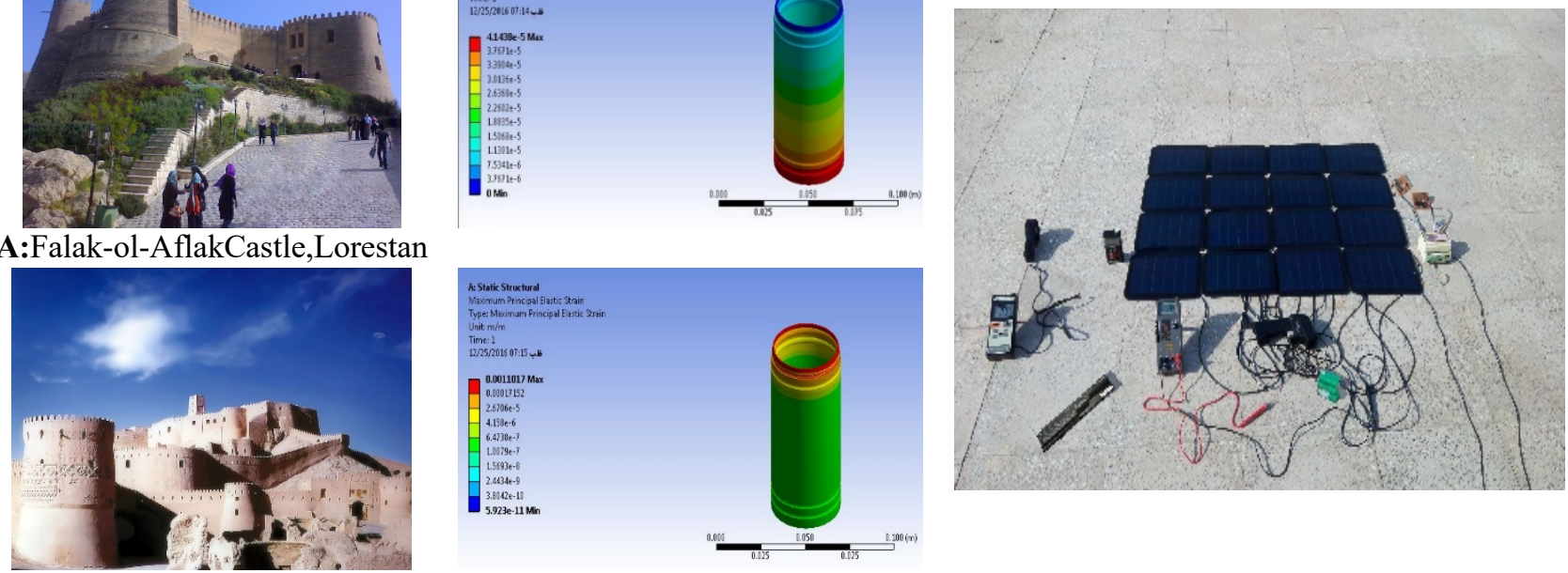

B:Arge Bam, Kerman
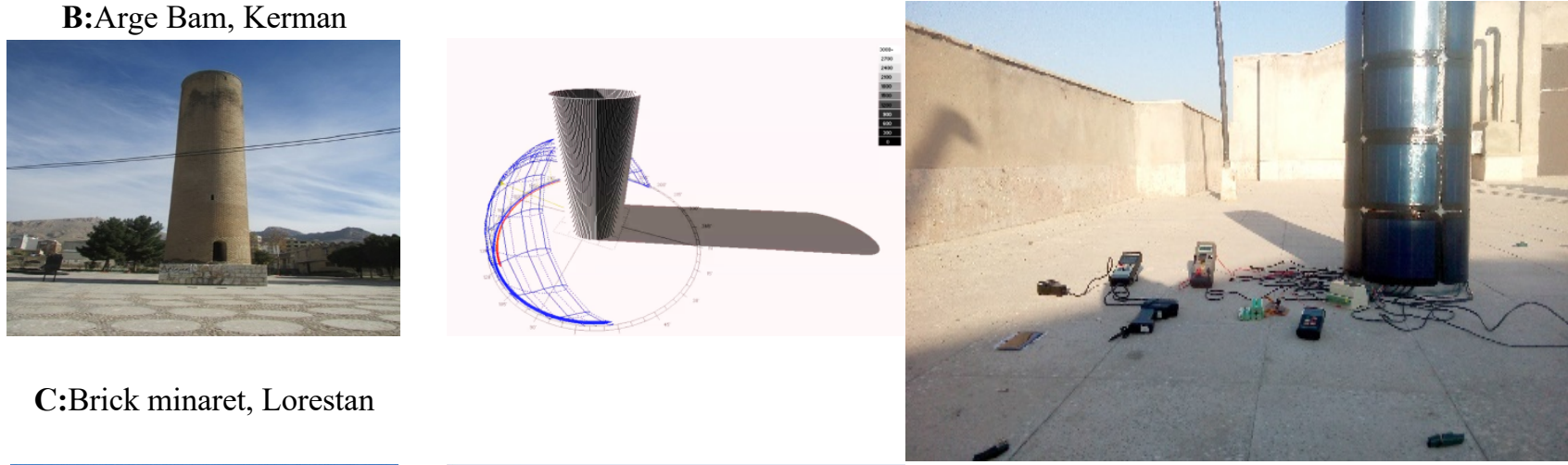

C:Brick minaret, Lorestan

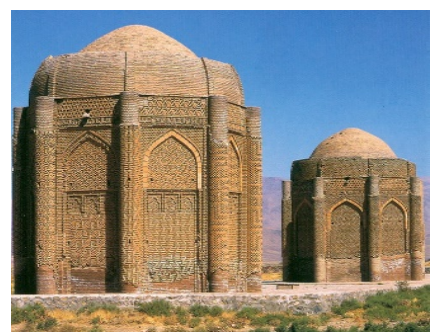

D:Kharaghan, Zanjan
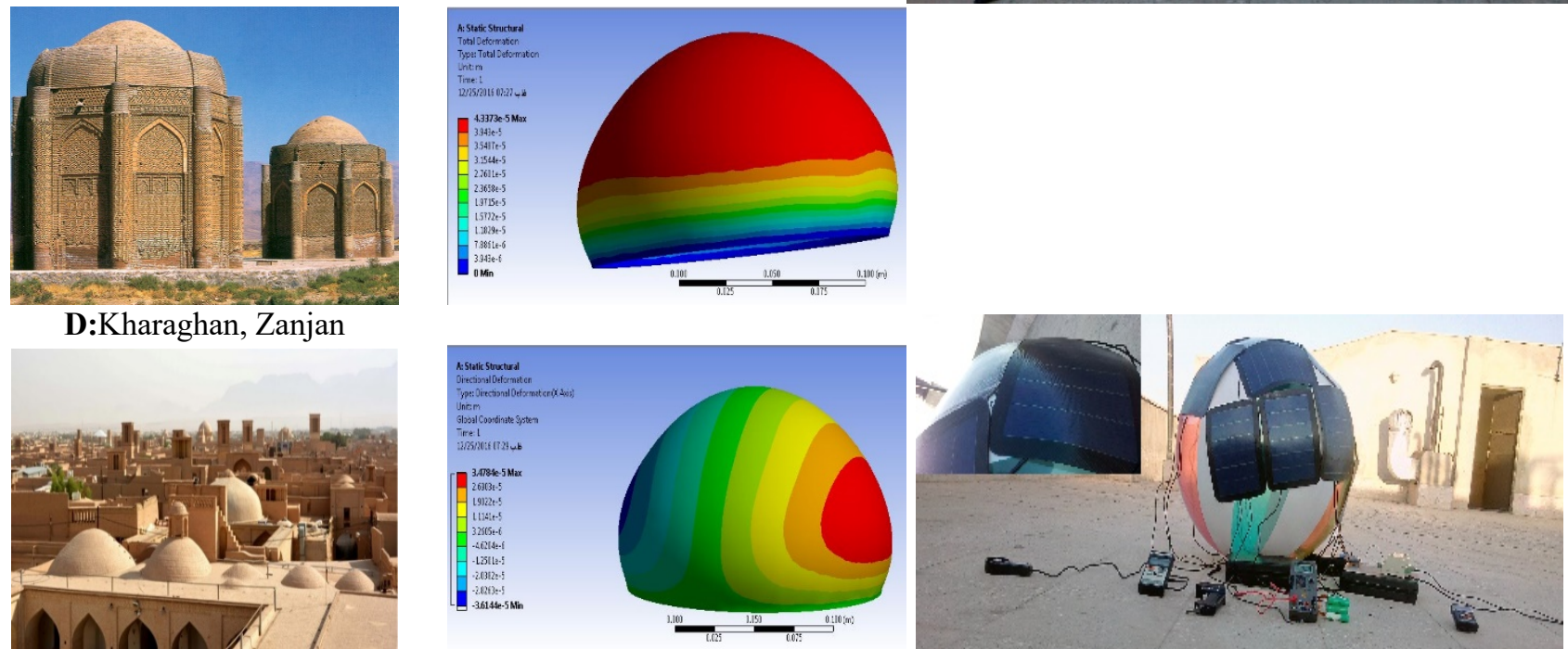

E: Yazd, Isfahan and Kerman Domes
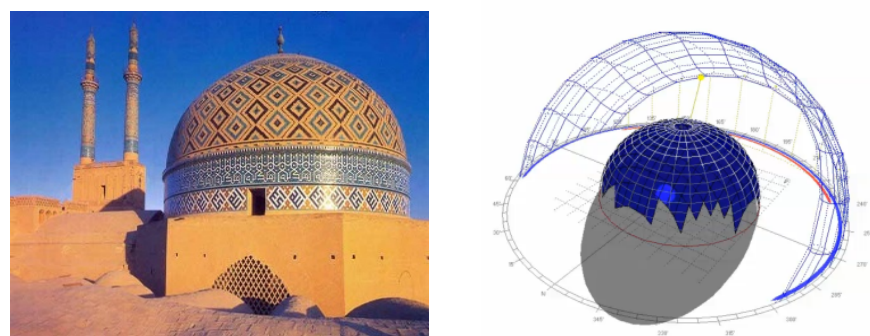

F:Jameh Mosque, Yazd

Fig. 2. Iran's most magnificent buildings and Simulation steps up real test 
Relying on the scale of the rectangular-shaped panel, the testing surface was chosen to be $1 \mathrm{~m}^{2}$ [27]. The most effective fitting surface set by the choice of $1 \mathrm{~m}$ solar panels are going to be $9744 \mathrm{~cm}^{2}$, furthermore because the number of panels used is sixteen. If the panel's marginal surface is deducted from the entire surface, then the effective photovoltaic surface in the electrical style relations becomes $6996 \mathrm{~cm}^{2}$ and the effective surface in geometric design relations of the structures are going to be $9744 \mathrm{~cm}^{2}$. To connect the temperature module, RS232 port and LabVIEW software package were used. This software advantages from a graphical programming language that contributes to operating simplicity. The Temperature was accurately regarded as the most necessary factor influencing the power generation of flexible photovoltaic systems. Microcontroller sends every 50 milliseconds the information of 16 temperature sensors via the serial connection, and once received by LabVIEW, displays it and stores every half-hour in an excel file in period of time. The maximum solar panel power is obtained from the product of voltage value (in open circuit mode) times the currentprice (in contact mode) and fill issue constant. Fill issue is mathematically similar to the current-voltage coverage arc, and the additional its value approaches one, the higher quality of the solar system. Fill factor (FF) calculated according to Equation (1) on the surfaces [28], [29].

$F F=\frac{V_{M P P} \times I_{M P P}}{V_{O C} \times I_{S C}}$

The efficiency of the photovoltaic system is one of the most important outdoor evaluation variables. Performance $(\eta)$ calculated by Equation (2) [30].

$\eta=\frac{P / s_{t}}{I}$

Where in the above relation, $\mathrm{I}$ is equal to the irradiance set on the array surface with unit $\mathrm{W} / \mathrm{m} 2$ and $\mathrm{St}$ is array surface with unit $\mathrm{m}^{2}$ and $\mathrm{P}$ is system power at the desired point with unit W. Using this indexation relation, calculating power dissipation in shadowing mode, temperature variations, dust drop, light reflection and irradiance on the solar panel was undertaken. To draw the graphs related to the performance curve and voltage-current diagrams as well as the effect of variables on power, voltage and current, Excel 2013 and Minitab 17.3 and Design Expert 7, Autodesk Ecotect were used. Ultimately, the optimal system Power was evaluated by Taguchi and RSM methods. . The orthogonal arrays of Taguchi experiments for the design $\left\{\operatorname{Lg}\left(3^{1} \times 3^{3}\right)\right\}$ evaluated the system performance over different surfaces. The experimental result transformed into the $\mathrm{S} / \mathrm{N}$ ratios, mainly three types: smaller-the-better, nominal-the-best in Equation 3, and largerthe-better in Equation 4 [24].

$$
\begin{aligned}
& S / N=10 \log \left(\frac{\bar{y}}{s_{y}^{2}}\right) \\
& \mathrm{S} /{ }_{N}=-10 \log \left(\frac{1}{n} \sum_{i=1}^{n} \frac{1}{y^{2}}\right)
\end{aligned}
$$

Where $\mathrm{n}$ is the number of trials of the same level with the aim of always keeping maximize of the $\mathrm{S} / \mathrm{N}$ ratio. A parameter level corresponding to the maximum average $\mathrm{S} / \mathrm{N}$ ratio called the optimum level parameter. The predicted value of $\mathrm{S} / \mathrm{N}$ ratio $\left(\eta_{\text {opt }}\right)$ at optimum parameter levels analyzed by Equation 5 as follows[24]:

$\eta_{\text {opt }}=\bar{n}+\sum_{i=1}^{k}\left(n_{m i}-\bar{n}\right)$

Where $\bar{n}$ is the average $\mathrm{S} / \mathrm{N}$ ratio of all experimental runs, $k$ is the number of control factors, and $n_{m i}$ is the mean $\mathrm{S} / \mathrm{N}$ ratio for $\mathrm{i}^{\text {th }}$ control factor corresponding to optimum parameter level.

The testing step is divided into three parts: flat, cylindrical and spherical surfaces. Flexible panels are connected in the system in series and the system is separately designed from the local power network. The assessment step was carried out on the roof of residential building in three consecutive days for each surface. Local meteorological data near the system was measured and recorded by various devices. Irradiance data for each panel perpendicular to the surface was measured by the irradiance recorder. Meteorological data for the 9-day test was also obtained from Meteorological Station and direct measurement devices connected to the LABVIEW software.

Box-Behnken designs is divided into three parts: flat, cylindrical and spherical test surfaces. The assessment step was carried out with 51 Runs in nine consecutive days was showed in table 2.

Table 2. Levels and responses in RSM.

\begin{tabular}{|c|c|c|c|c|c|}
\hline Factor & Name & Units & Low Act. & High Act. & Mean \\
\hline A & Irr. & $\mathrm{W} / \mathrm{m}^{\wedge} 2$ & 200 & 1100 & 650 \\
\hline B & Temp. & ${ }^{\circ} \mathrm{C}$ & 20 & 50 & 35 \\
\hline C & W.S & $\mathrm{m} / \mathrm{s}$ & 0 & 3 & 1.5 \\
\hline D & Flex. & Degree & Flat & Hemisphere & Levels \\
\hline
\end{tabular}

Table 2 represents the testing factors and surfaces. In this experiment, 4 factors were selected, the irradiance power variable in 6 levels, and the variables of temperature, wind speed, and system's average arc in three levels. The arc at level (1) is equivalent to the system test in flat mode, and level (2) relates to the system test on the hemisphere surface and level (3) associates with the deployment on the cylindrical surface. The irradiance power variable is classified from sunrise to sunset from 200 to 1100 watts per $\mathrm{m}^{2}$.

Engineering economics, through project's economic analysis, addresses the study of different investment projects and choosing the most economical ones or making a decision to reject or accept the implementation of specific projects using mathematical techniques and quantitative evaluation criteria. In this research, we have used COMFAR software version 3. The engineering economics criteria used in the economic performance test are Net present value (Equation 6), Benefitcost ratio and Internal Rate and Payback Period.

$$
N P V=N C F_{0}+\frac{N C F_{1}}{(1+i)}+\frac{N C F_{2}}{(1+i)^{2}}+\frac{N C F_{t}}{(1+i)^{t}}
$$

\section{Results and Discussion}


Flexible photovoltaic array consists of 16 flexible solar panels of JNPsolar $3 \mathrm{~W}-12 \mathrm{~V}$ model serially connected on different surfaces. Fig.3. Illustrates the analysis of flexible array power when deployed on different surfaces. By understanding the amount of variance and its generating source, the best performance conditions in systems were simultaneously predicted, which this is one of the advantages of using Taguchi test method for the system. Figure 3(A-C) shows the system's ability to produce a perfectly smooth air from sunrise to sunset at the different surfaces. The sun rose from the east, the radiant power in the eastern aspect rose sharply after the dawn, and in less than 3 hours after rising, the amount reached a maximum peaked at 1058 watts per square meter. The radiant power in this case was recorded at less than 3 hours over 1,000 watts per square meter and reached a peak of 450 watts per square meter in the middle of the day around 12:30. After 13 o'clock, the intensity of the irradiation on the eastern side dropped with gentle slopes and reached its lowest point in the evening. The radiant power on the southern side of the test surface is seen after the sun rose with a gentle slope and reached about 14 hours at its peak at 695 watts per square meter. These changes stabilized the shape of the curve surfaces as Sin Shape.

The curve shown in Figure 3C in the system's test on the hemisphere was in real terms: the power was rising immediately after sunrise and sunlight, reaching a peak at 63.8 W. After passing through the system and increasing the temperature, the power of the pipeline was reduced and went down to about 11 am for a short time. In the middle of noon (from 11:00 to 12:30), the capacity of the system's power was increased at the spherical level and approached the normal line $(55.5 \mathrm{~W})$. In the afternoon, after 14:30, the power is rising, and this generates a relative peak of $57 \mathrm{~W}$. During the sunset, the power was reduced by decreasing radiation power, and at the moment of the sunset, the system produced less than 49 watts of power.

If Taguchi test design and RSM Method analyzed based on the maximum power generation capability, the output of the test analysis would be in accordance with Fig. 4. In this test, power has been evaluated based on "more is better". The interaction of variables of irradiance, temperature, flexibility and wind speed was analyzed. In the axis of the lengths, the graphs of the levels of variables are specified. The vertical axis represents the mean SNR. Vertical axis, shows the larger the SNR, the closer the target, and no difference between choosing "more, better" and "or less, better" will exist. If the irradiance situates at level (1), more power is actually available. Irradiance will have a common property on systems up to the level (3), i.e., irradiance ranges $400-600 \mathrm{~W} / \mathrm{m}^{2}$; then, the effectiveness is a little diminished, but it is still optimal for the system and satisfies the objective. But in the irradiance power above the level (5), i.e., level (6) and above, the system is aimed in the opposite direction. With an overall glance to the irradiance power and SNR group, there can be seen that irradiance power could greatly influence the purpose of the potential of electric power generation by distancing away from the midline and high failure. The ambient temperature situated in the second group and temperature level (3) had the greatest impact on the system's purpose. Changes in wind speed from level (1) to level (2) were very effective at the system's aim and could alter the conditions in a way to generate power at high ambient temperatures. The flexibility or angle of the photovoltaic system showed that changing in this factor, namely, the use of the system in flat mode (level 1), or when deployed on a spherical surface (level 2) or on a cylindrical surface (level 3) can have an impact on generating maximum power objective. System's angle group and SNR revealed that: level (1) defined as using the system at the flat surface can have the greatest impact on the system.

The application of the system on the level (2), meaning the application of the system on the spherical surface, despite its situation at the vicinity of the intermediate line of power production target, is more optimal than levels (1) and (3). Level (3) meant the application of the system over a cylindrical surface is more optimal than the flat surface, but the power production is maximum at level (2). Therefore, the use of the system in flat mode on the roof like the bitumen is not prioritized. As well as, if in a farm at the same time we have both grain storage silos and biogas reservoir, application of the system in these conditions will be preferable over a hemisphere surface, which means biogas reservoir. Therefore, the priority will be given to using the solar energy conversion system to electrical energy based on flexible solar panels at various levels, as defined below:

- The first priority is the second level of radiation (500-800 watts per square meter) and the first level of temperature $\left(20-30{ }^{\circ} \mathrm{C}\right)$ and the first level of wind $(0-1 \mathrm{~m} / \mathrm{s})$ on the cylindrical surface.

- The second priority is the second level of radiation (500$800 \mathrm{~W} / \mathrm{m} 2)$ and the first level of temperature $\left(20-30{ }^{\circ} \mathrm{C}\right)$ and the first level of wind $(0-1 \mathrm{~m} / \mathrm{s})$ on the hemisphere surface.

- The third priority is the third level of radiation (800-1100 $\mathrm{W} / \mathrm{m} 2)$ and the first level of temperature $\left(20-30^{\circ} \mathrm{C}\right)$ and the third level of the wind $(2-3 \mathrm{~m} / \mathrm{s})$ on the flat surface.

The results imply that the net present value of the flexible system, when deployed on the flat surface, amounts to 6.747 million rials and its internal rate of return is $23.82 \%$ as well as the return period of capital is 9.24 years. additional to that, the NPV of the flexible system when deployed on the cylindrical and hemispherical surfaces are respectively up to 9.952 and 10.830 million rials, and their internal rates of return are $26.70 \%$ and $27.46 \%$, as well as their return periods of capital are 8.24 and 8.02 years, respectively. Important highlights are:

1. By increasing discount rate, NPV for all three systems is reduced.

2. within the system deployed on a flat surface at the project's $23^{\text {rd }}$ discount rate, the present value of design's costs and revenues has been constant.

3. within the system deployed on a cylindrical surface at the project's discount rate of $26^{\text {th }}$, the current value of design's costs and revenues has been constant.

4. within the system deployed on a hemispherical surface at the project's discount rate of $27^{\text {th }}$, the current value of design's costs and revenues is equal. 
5. By increasing the discount rate from $23^{\text {rd }}$ upwards at the flat surface, $26^{\text {th }}$ upwards at the cylindrical surface and $27^{\text {th }}$ upwards at the hemispherical surface, the
NPV of the costs gets more than one of the revenues and becomes non-economic.
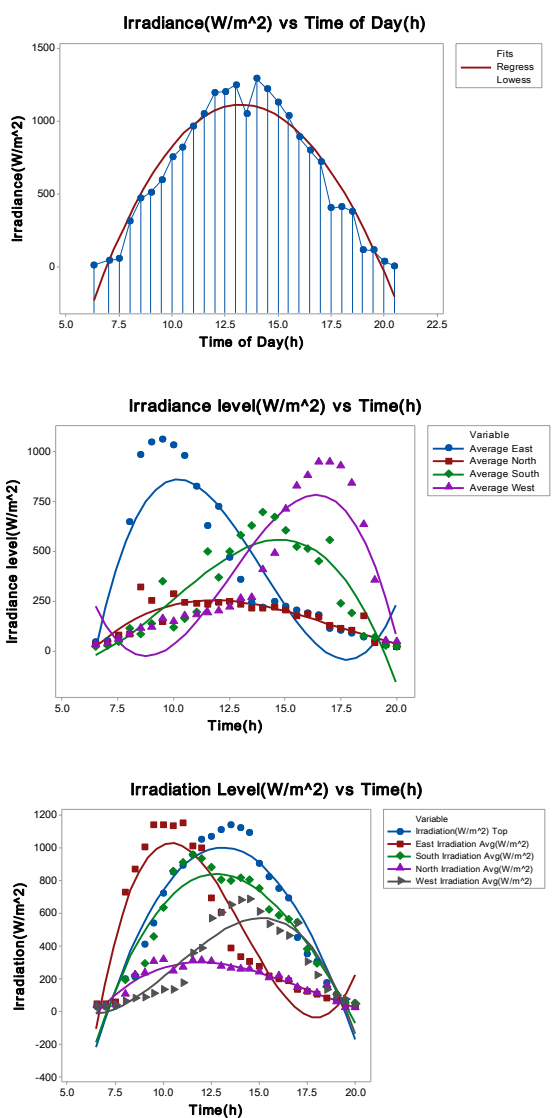

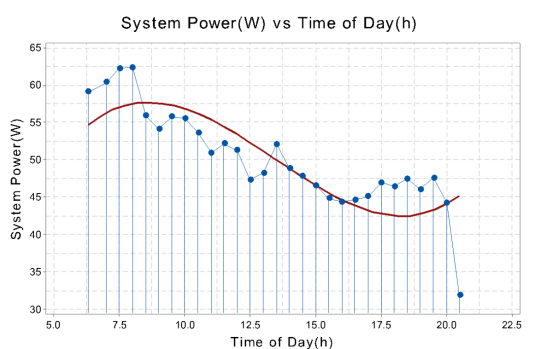

A: flat surfaces $(\mathrm{FF}=0.73)$

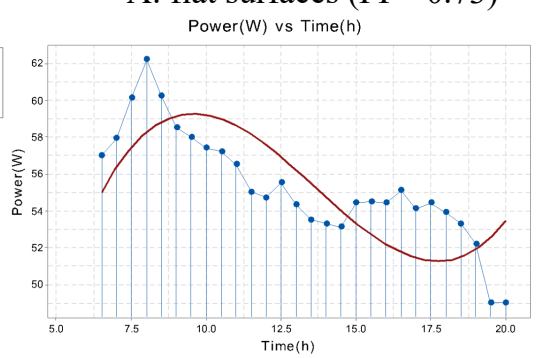

B: Cylindrical surfaces $(F F=0.88)$

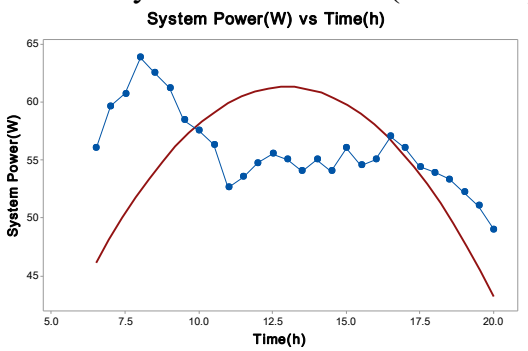

$\mathrm{C}$ : Hemispheric surfaces $(\mathrm{FF}=0.84)$
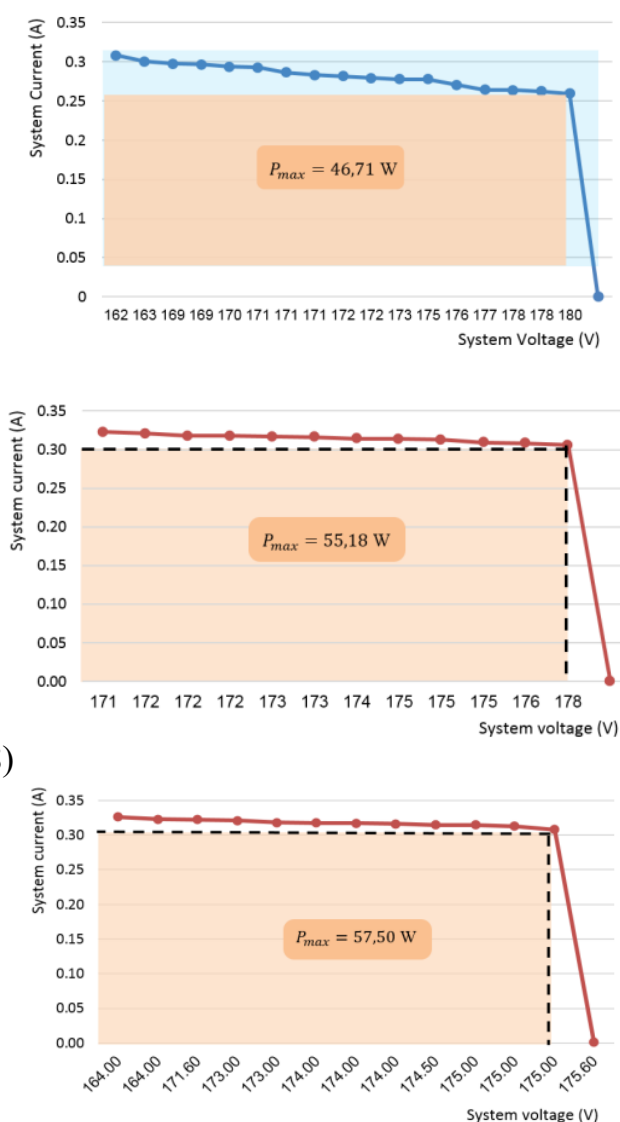

Fig. 3. Electrical and Technical Efficiency of Systems

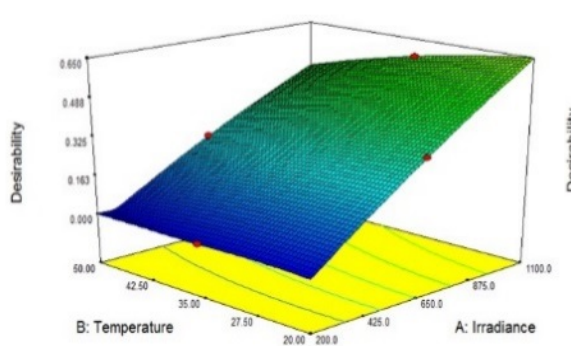

Flat surfaces $(\mathrm{FF}=0.73)$

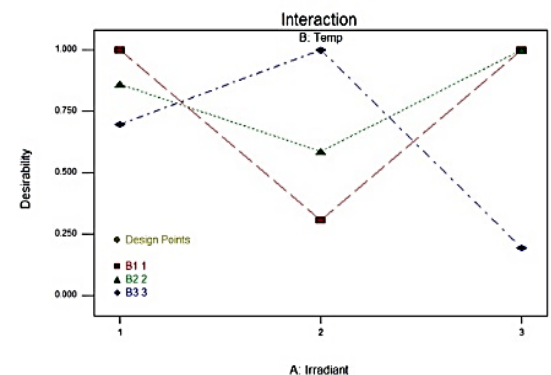

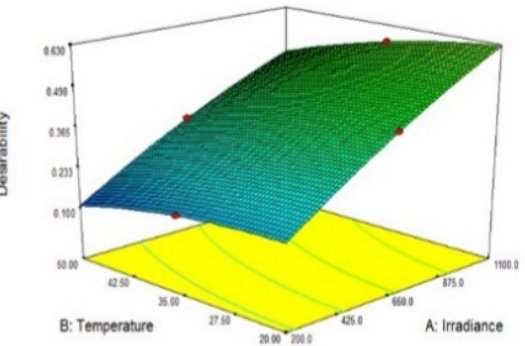

B: Cylindrical surfaces $(\mathrm{FF}=0.88)$ RSM Method

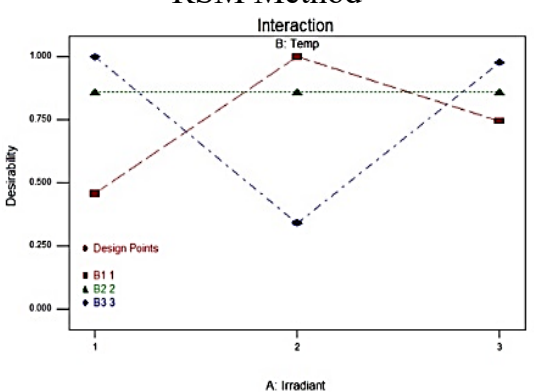

Taguchi Method

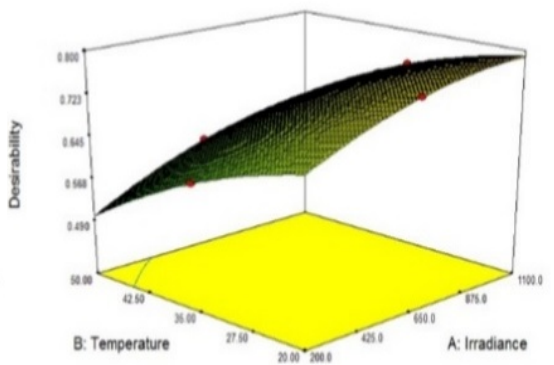

$\mathrm{C}$ : Hemispheric surfaces $(\mathrm{FF}=0.84)$

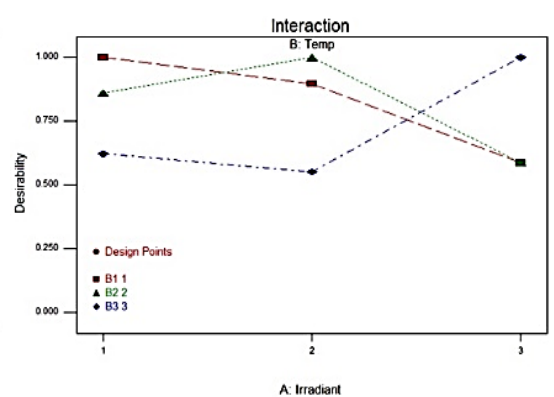

Fig. 4. Results of the average analysis and factor of interaction in Taguchi impacts (signal-to-noise ratio) and RSM 


\section{Conclusion}

In fabrication duration and implementation of flexible solar systems, the net flows were negative and in the system when deployed on the flat, cylindrical and hemispherical surfaces, respectively from $9.24,8.24$ and 8.02 to the end of the operation period, cumulative net flows of designs were positive and steadily risen. Moreover, the normal PP of the capital in the system when deployed on the flat surface was 9 years, as well as it was 8 years in the case of deployment on the cylindrical and hemispherical surfaces (normal PP of the system on the hemispherical surface is equivalent to 8.07 , so its year can be considered 7). The summary of the results is presented in Table 3.

As such, in the flat-surface deployment system, a $20 \%$ increase in project costs increased the internal rate by $21.30 \%$; as well as a $20 \%$ drop in revenues will lead to a reduction in the project's internal rate of return by $22.99 \%$. In addition, in a flexible solar system when deployed on cylindrical and hemispherical surfaces with an increase of $20 \%$ in project costs, the internal rate of return becomes $25.59 \%$ and $24.48 \%$, respectively; coupled with, with a $20 \%$ drop in revenues, project's internal rate of return will reduce $25.79 \%$ and $26.53 \%$, respectively. Therefore, the order of being economic in the systems will also be related to a flexible solar system when deployed on the hemispherical, cylindrical and flat surfaces. The response of the system was at a level of 50 when deployed on a flat surface: exploitation flexible systems with nominal performance lower than photovoltaic crystalline systems haven't reached the desired quality and aren't competitive with them. However in the same research, flexible photovoltaic systems, with a very low cost of production, will compete with conventional systems in massive quantities [20], [23], [30].In a study of flexible solar systems in greenhouses, Cossu et al. found that the effect of radiation and surface temperature on the power production function was very effective and the electrical energy generated by the system was highly dependent on these [31]. Kevin and Graalso reported the most important parameters in the power and performance of a flexible solar system, according to ambient temperature and radiation intensity, but did not investigate the combined effect of variables [27]. Some of suggestions from this research are summarized as follows:

- Systems should be used in optimal wind speed, medium radiation, and minimum temperature.

- Flexible solar systems are recommended for use in cylindrical elements (communication antenna systems, flags, etc.) and villages (silos, cylindrical towers, etc.).

- For using systems on biogas reservoirs, since the average radiation in the north and the western part of this level is lower than the other levels, it is better to install the associated electrical systems in these areas.

- Considering the proper composition of the hemisphere in desert and desert areas due to the characteristics of traditional air conditioning, some countries are recommended to use a flexible system on the hemisphere in desert buildings, domes, dome greenhouses to provide part of the power Electric to be used.

Table 3. Systems' behavioral assessment for "more is better" power characteristic

\begin{tabular}{|c|c|c|c|c|c|c|c|c|}
\hline Power Plan & MP Taguchi (W) & MP RSM (W) & $\mathrm{FF}(\%)$ & S.P $(\%)$ & $\mathrm{OCV}(\mathrm{V})$ & $\operatorname{SCC}(\mathrm{A})$ & IRR & NPV \\
\hline Flat S. & 57.84 & 56.6 & 73 & 7.1 & 185 & 0.34 & 23.8 & 6.7 \\
\hline Cylindrical S. & 59.87 & 57.71 & 88 & 7.4 & 179 & 0.35 & 26.7 & 9.9 \\
\hline Hemisphere S. & 58.27 & 61.14 & 84 & 7.4 & 178 & 0.36 & 27.4 & 10.8 \\
\hline
\end{tabular}

\section{References}

[1] Y. Y. Hong, A. A. Beltran, and A. C. Paglinawan, "A robust design of maximum power point tracking using Taguchi method for stand-alone PV system," Appl. Energy, vol. 211, no. July 2017, pp. 50-63, 2018.

[2] Manjola Banja, Martin Jégard, “An Analysis of Capacity Market Mechanism for Solar Photovoltaics in France," International Journal of Smart Grid - ijSmartGrid, Vol 3, No 1, pp. 10-18, 2019.

[3] IEA, "Sustainable Technology at the Brundtland Centre Denmark," Int. Energy Agency, vol. 9, 2017.

[4] H. M. Hasanien, "Performance improvement of photovoltaic power systems using an optimal control strategy based on whale optimization algorithm," Electr. Power Syst. Res., vol. 157, pp. 168-176, 2018.
[5] L. Fara and D. Craciunescu, "ScienceDirect Sustainable Solutions for Energy and Environment, EENVIRO Output Analysis of Stand-Alone PV Systems: Modeling, Simulation and Control," Energy Procedia, vol. 112, pp. 595-605, 2017.

[6] O. Oduyemi and M. Okoroh, "Building performance modelling for sustainable building design," Int. J. Sustain. Built Environ., vol. 5, no. 2, pp. 461-469, Dec. 2016.

[7] R. Zeb, L. Salar, U. Awan, K. Zaman, and M. Shahbaz, "Causal links between renewable energy, environmental degradation and economic growth in selected SAARC countries: Progress towards green economy," Renew. Energy, vol. 71, pp. 123-132, Nov. 2014.

[8] A. K. Shukla, K. Sudhakar, P. Baredar, and R. Mamat, "BIPV based sustainable building in South Asian countries," Sol. Energy, vol. 170, pp. 1162-1170, Aug. 2018. 
[9] S. Rabab Mudakkar, K. Zaman, H. Shakir, M. Arif, I. Naseem, and L. Naz, "Determinants of energy consumption function in SAARC countries: Balancing the odds," Renew. Sustain. Energy Rev., vol. 28, pp. 566-574, Dec. 2013.

[10] S. Edalati, M. Ameri, M. Iranmanesh, H. Tarmahi, and M. Gholampour, "Technical and economic assessments of grid-connected photovoltaic power plants: Iran case study," Energy, vol. 114, pp. 923-934, 2016.

[11]M. Zohoori, "Exploiting Renewable Energy Sources in Iran,” Interdiscip. J. Contemp. Res. Bus., vol. 4, no. 7, pp. 849-862, 2012.

[12] M. Zohoori, "INTERDISCIPLINARY JOURNAL OF CONTEMPORARY RESEARCH IN BUSINESS Exploiting Renewable Energy Sources in Iran," NOVEMBER, vol. 4, no. 7, 2012.

[13] K. H. Solangi, M. R. Islam, R. Saidur, N. A. Rahim, and H. Fayaz, A review on global solar energy policy, vol. 15, no. 4. 2011, pp. 2149-2163.

[14]D. Salehi-Isfahani and M. H. Mostafavi-Dehzooei, "Cash transfers and labor supply: Evidence from a largescale program in Iran,” J. Dev. Econ., vol. 135, pp. 349367, Nov. 2018.

[15] M. Raufi Rad, Designing Solar Building Systems in Iran(Persian), First Edit. National Iranian Oil Company Publications, 2006.

[16]H. K. Ghritlahre and R. K. Prasad, "Application of ANN technique to predict the performance of solar collector systems - A review," Renew. Sustain. Energy Rev., vol. 84, no. December 2017, pp. 75-88, 2018.

[17] A. Demiroren and U. Yilmaz, "Analysis of change in electric energy cost with using renewable energy sources in Gkceada, Turkey: An island example," Renewable and Sustainable Energy Reviews, vol. 14, no. 1. pp. 323-333, 2010.
[18] A. Sheikhi, A. M. Ranjbar, and H. Oraee, "Financial analysis and optimal size and operation for a multicarrier energy system,” Energy Build., vol. 48, pp. 71-78, 2012.

[19] JMP, “JNP,” jmpsolarpower, 2017. [Online]. Available: https://jmpsolarpower.com/. [Accessed: 15-Feb-2018].

[20] J. J. J. Bloem, C. Lodi, J. Cipriano, and D. Chemisana, "An outdoor Test Reference Environment for double skin applications of Building Integrated PhotoVoltaic Systems," Energy Build., vol. 50, pp. 63-73, Jul. 2012.

[21] J. Yan, G. Luo, B. Xiao, H. Wu, Z. He, and Y. Cao, "Origin of high fill factor in polymer solar cells from semiconducting polymer with moderate charge carrier mobility," Org. Electron., vol. 24, pp. 125-130, Sep. 2015.

[22] R. Z. Alshali, N. A. Salim, R. Sung, J. D. Satterthwaite, and N. Silikas, "Qualitative and quantitative characterization of monomers of uncured bulk-fill and conventional resin-composites using liquid chromatography/mass spectrometry," Dent. Mater., vol. 31, no. 6, pp. 711-720, Jun. 2015.

[23] K. M. Graff and B. Eng, "Environmental Effects on the Operation of Triple-Junction Flexible Photovoltaic Panels," 2014.

[24] Sivaraos, K. R. Milkey, A. R. Samsudin, A. K. Dubey, and P. Kidd, "Comparison between Taguchi Method and Response Surface Methodology (RSM) in Modelling CO 2 Laser Machining," JJMIE Jordan J. Mech. Ind. Eng., vol. 8, no. 1, 2014.

[25] E. A. Thornton and Y. A. Kim, "Thermally-Induced Bending Vibrations of a Flexible Rolled-up SolarArray," J. Spacecr. Rockets, vol. 30, no. 4, pp. 438-448, Jul. 1993.

[26] K. L. Chopra, P. D. Paulson, and V. Dutta, “Thin-film solar cells: an overview," Prog. Photovoltaics Res. Appl., vol. 12, no. 23, pp. 69-92, Mar. 2004.

[27] S. Şevik and M. Abuşka, "Thermal performance of flexible air duct using a new absorber 